\title{
La distribución de la tierra y el crecimiento económico de la campaña de Buenos Aires. Un estudio de la región oeste, 1839-1867
}

\section{Land Distribution and the Economic Growth of the Buenos Aires Campaign. A Study of the Western Region, 1839-1867}

\author{
María Fernanda Barcos* \\ (D) 0000-0002-7698-8284 \\ Universidad Nacional de La Plata-Conicet, Argentina \\ mfbarcos@hotmail.com
}

Resumen: En Buenos Aires, el periodo que transcurrió entre 1839 y 1869 se caracterizó por un crecimiento económico casi constante. Dicho proceso generó una creciente desigualdad en la distribución de la riqueza (fundamentalmente de la tierra) pero produjo una importante movilidad social, sobre todo entre 1839 y 1855 . La región oeste presenta particularidades bien marcadas en el proceso señalado que aún no han sido estudiadas en detalle. A partir del análisis conjunto del impuesto de la contribución directa y los expedientes de tierras, se estudian las causas del movimiento diferencial que se operó allí. Se analizan los partidos de Chivilcoy, Mercedes y Suipacha (partido de la Guardia de Luján hasta 1845) porque sintetizan muy bien los cambios operados en la región de estudio.

Palabras clave: Buenos Aires; crecimiento económico; distribución de la riqueza; tierras; Mercedes; Chivilcoy; movilidad social.

* Agradezco especialmente los valiosos comentarios de los pares evaluadores(as) a la versión preliminar del artículo. El presente trabajo ha sido aprobado para su publicación en el año 2014, razón por la cual puede estar omitiendo bibliografía publicada con posterioridad. 
Abstract: In Buenos Aires, the period between 1839 and 1869 was characterized by almost constant economic growth. Although this process created growing inequality in the distribution of wealth (mainly of land) it also led to significant social mobility, particularly between 1839 and 1855 . The west region has distinct particularities in the process that have yet to be studied in detail. A joint analysis of the direct contribution tax and land records was used to study the causes of the distinct movement that took place there. The parties of Chivilcoy, Mercedes and Suipacha (formerly the Luján's Guard party until 1845) are analyzed because they provide a detailed summary of the changes that took place in the region under study.

Key words: Buenos Aires; economic growth; wealth distribution; land; Mercedes; Chivilcoy; social mobility.

Fecha de recepción: 26 de septiembre de 2014 Fecha de aceptación: 30 de abril de 2015

\section{INTRODUCCIÓN}

— n Buenos Aires, el periodo que transcurrió entre 1839 y 1869 se caracterizó L por un crecimiento económico casi constante a pesar de las alteraciones
políticas. Durante ese lapso aconteció el segundo gobierno de Juan Manuel de Rosas (1835-1852). Inmediatamente después de la caída de esa administración, se inició un periodo de profunda inestabilidad en el que se produjeron fuertes enfrentamientos al interior de la alianza antirrosista (1852-1854). En 1854 Buenos Aires se transformó en Estado, dictó una Constitución y se mantuvo separada de la Confederación Argentina hasta 1862. A partir de esta fecha comenzó el denominado periodo de Organización Nacional inaugurado con la presidencia de Bartolomé Mitre (1862-1868) y continuado por la de Domingo F. Sarmiento (1868-1874).

Los vaivenes políticos que se sucedieron durante este lapso impactaron en la estructura económica y social, provocaron modificaciones institucionales y generaron una dinámica específica en la relación con los indígenas por la puja en torno a la expansión de la frontera. Respecto de esto último, durante el periodo rosista, las relaciones interétnicas incluyeron la guerra pero también el "negocio pacífico", cuestión que permitió expandir la superficie bajo control hacia el centro y sur de la provincia. Luego de la caída de

\section{()(1) $(9$}


Rosas y con el posterior enfrentamiento entre la Confederación Argentina y el Estado de Buenos Aires, se abrió un ciclo de conflictividad interétnica que recién culminó parcialmente con una serie de negociaciones y tratados en los que se fijaron las condiciones para pacificar nuevamente la frontera, la cual se había retrotraído fuertemente. ${ }^{1}$

Con la unificación nacional a partir de 1862 y hasta la denominada "Conquista del Desierto" iniciada en 1879, la política indígena incluyó la oferta de tratados de paz a una gran cantidad de caciques (con entrega de raciones y sueldos a ciertos grupos y favoreciendo la instalación de otros como "indios amigos") sobre todo en el oeste y sur de la provincia. Paralelamente se generó una dinámica fluctuante de ruptura de relaciones y recomposición de tratados con otros grupos que estaban más afectados por los avances fronterizos que se dieron entre 1864 y 1876 (Jong, 2007; Lanteri y Pedrotta, 2009, pp. 101-129; Ratto, 2012, pp. 357-380).

Durante todos estos años se generó una creciente desigualdad en la distribución de la riqueza pero también se produjo una importante movilidad social. Con riqueza nos referimos fundamentalmente a la tierra rural y/o ejidal aunque también construcciones -estancias, quintas, chacras y solares- puesto que estas estaban incluidas en el ramo "otros bienes". Existen ya varios trabajos que han demostrado la movilidad ascendente de los pequeños y medianos propietarios durante el periodo rosista pero menos se conoce respecto del periodo inmediatamente posterior y anterior a la denominada "Argentina Moderna". ${ }^{2}$ Actualmente se ha avanzado en la temática con una mirada tanto general como particular y, en esta línea, nos interesó incorporar más regiones al debate.

${ }^{1}$ La bibliografía plantea desde un retroceso de 4000000 de hectáreas hacia 1855 a un paso de 11600000 a 11000000 de hectáreas. Valencia (2005); Barsky y Djenderdjian (2003).

${ }^{2}$ No hay homología entre productores y propietarios, hay muchos productores que no son propietarios y al revés. También la definición de propiedad es compleja y preferimos hablar de "derechos de propiedad", concepto que incluye un vínculo más formal con el factor pero que no implica necesariamente la presencia de títulos. Por otra parte, en este trabajo se define el tamaño de los propietarios en relación con el capital que poseen y no en función del tamaño de la propiedad. Para ello nos centramos en los parámetros que utilizaron Gelman y Santilli, los pequeños tienen un capital menor a $\$ 5000$, no tenían posibilidades de acumular, en contraste con los comprendidos dentro de la franja \$10 000-19 999, que constituían los "medianos en proceso de acumulación", estando los "ricos" dentro de la cohorte de $\$ 40000$ 79999 y los "poderosos" a partir de los $\$ 80$ 000. Respecto de todos estos debates, véase Barcos (2011); Garavaglia (1999, 2004); Gelman y Santilli (2006).

\section{()(1) $(9$}


Escogimos la región oeste de la provincia de Buenos Aires porque presenta particularidades que invitan a profundizar el análisis desde lo local. Allí se practicaba tradicionalmente tanto la ganadería (vacuna y ovina) como la agricultura cerealera y se ubicaban varios establecimientos dedicados a la lechería. A partir de la década de los cincuenta la región experimentará el boom del lanar pero también contará con partidos como Chivilcoy que tendrán un fuerte crecimiento agrícola. Para el periodo considerado constituía una región relativamente protegida donde la modalidad de entrega de tierras incluyó mercedes reales, moderada composición y, sobre todo, enfiteusis. Esto devino un incipiente mercado de tierras producto de las transferencias -privadas y de derechos- entre particulares y de las compraventas.

Los precios del factor tuvieron un periodo de alza hasta 1828 y luego comenzaron a decaer hasta finales de la década de 1830 cuando se inició una nueva tendencia alcista -interrumpida unos años a inicios de los cincuentaque culminó a mediados de los sesenta, momento cercano al cierre de nuestro trabajo. La expansión ganadera de mediados de la década de 1810 fue la responsable de la rápida valorización de la tierra. Dicho movimiento se interrumpió con el emisionismo que desencadenó el bloqueo brasileño al puerto de Buenos Aires a partir de 1826, cuestión que se repetiría en 1838 y 1840 con el bloqueo francés. Así, la emisión de pesos papel junto con la interrupción del comercio parecen haber provocado una baja de precios. Recién a partir de 1840 se produjo un claro crecimiento de las exportaciones que parece reflejarse en los precios. Unos años antes, en 1836 y luego en 1838, Rosas había puesto en venta las tierras otorgadas en enfiteusis, cuestión que también influyó en la baja de los precios. Ya a partir de la década de 1850 se observa claramente el movimiento de valorización de la tierra, sobre todo durante los años posteriores a la caída de Rosas puesto que en la década de 1860 el incremento se moderó. La expansión de la ganadería ovina, y con ella la economía agroexportadora en conjunto, fueron las causantes principales del incremento de los precios, sumado al cierre de la frontera y las migraciones que incrementaron la demanda de tierras (Banzato, Barcos y D’Agostino, 2013, pp. 19-64; Garavaglia, 2004; Gelman y Santilli, 2015, pp. 153-186; Sabato, 1989).

Trabajaremos con dos partidos del oeste de la provincia de Buenos Aires, Mercedes (que incluyó el partido de Suipacha durante la mayor parte del periodo) y Chivilcoy, ambos de gran dinamismo. A inicios del periodo estudiado constituían una amplia región denominada Guardia de Luján, donde habitaban fundamentalmente pequeños y medianos labradores y algunos

\section{()(1) $(9$}


estancieros importantes. La población de la zona venía creciendo desde las primeras tres décadas del siglo XIX, cuestión que devino en la primera división jurisdiccional. En 1845 la porción más fronteriza -lindante con el río Salado- se separó de la Guardia de Luján y formó el partido de Chivilcoy. En 1854, la vieja Guardia fue rebautizada con el nombre de Villa Mercedes y en 1854 se generó la segunda división a raíz de la escisión de Suipacha por medio de la ley del 24 de octubre de 1864.

Si bien la actividad que se practicaba tradicionalmente en dichos partidos era mixta, desde la década de los cincuenta, y con más énfasis durante los años sesenta, las economías de cada zona tendieron a concentrarse en algunos sectores más que en otros. Mercedes se convirtió en el corazón lanero y comercial del oeste, con una fuerte impronta de población europea que constituía $24.7 \%$ del total en 1869; Chivilcoy, con otra cronología de ocupación y con menos población extranjera en el mismo año (18.4\%), consolidaba su especialización agrícola (Djenderedjian, 2008).

La fuente principal utilizada para este trabajo es el impuesto de la contribución directa complementado, a su vez, con duplicados de mensura, expedientes de trámite de escrituración de tierras, padrones demográficos, cedulas censales y recopilaciones de leyes. La contribución directa es una fuente impositiva que ha sido y sigue siendo ampliamente abordada por la historiografía debido a que brinda una serie de datos que contribuyen a explicaciones cada vez más completas sobre el crecimiento económico y la distribución de la riqueza. Para analizar el periodo se utilizaron los registros de 1839, 1855 y 1867 tanto por su calidad como también por la cercanía a los recuentos de población disponibles: 1838, 1855 y 1869. Además, existen trabajos previos que realizan este recorte y toman toda la provincia de Buenos Aires, esto nos permite dialogar con la mirada provincial y regional. Para el periodo 1839-1855 usamos también los datos de la contribución directa de 1845 y 1850 , estos adolecen de varios problemas y por eso fueron materia de recaudo. ${ }^{3}$ No obstante, esta ofrece información nominal muy rica que puede

${ }^{3}$ Para los años posteriores a 1839 la fuente adolece de una serie de problemas que deben ser necesariamente tenidos en cuenta; la década de 1840 fue muy ardua en materia de recaudación y el impuesto habría afectado a una proporción menor de pobladores debido a los embargos que se realizaron sobre los bienes de los unitarios y a las excepciones que se establecieron para los individuos que se mantuvieron fieles al régimen en la coyuntura política más complicada del rosismo. Sumado a esto, en 1841 fueron también exceptuados de pagar el impuesto todos los ciudadanos en armas. Según Garavaglia (2003), la presión reclutadora 
Mapa 1. Mercedes, Suipacha y Chivilcoy en la Provincia de Buenos Aires.

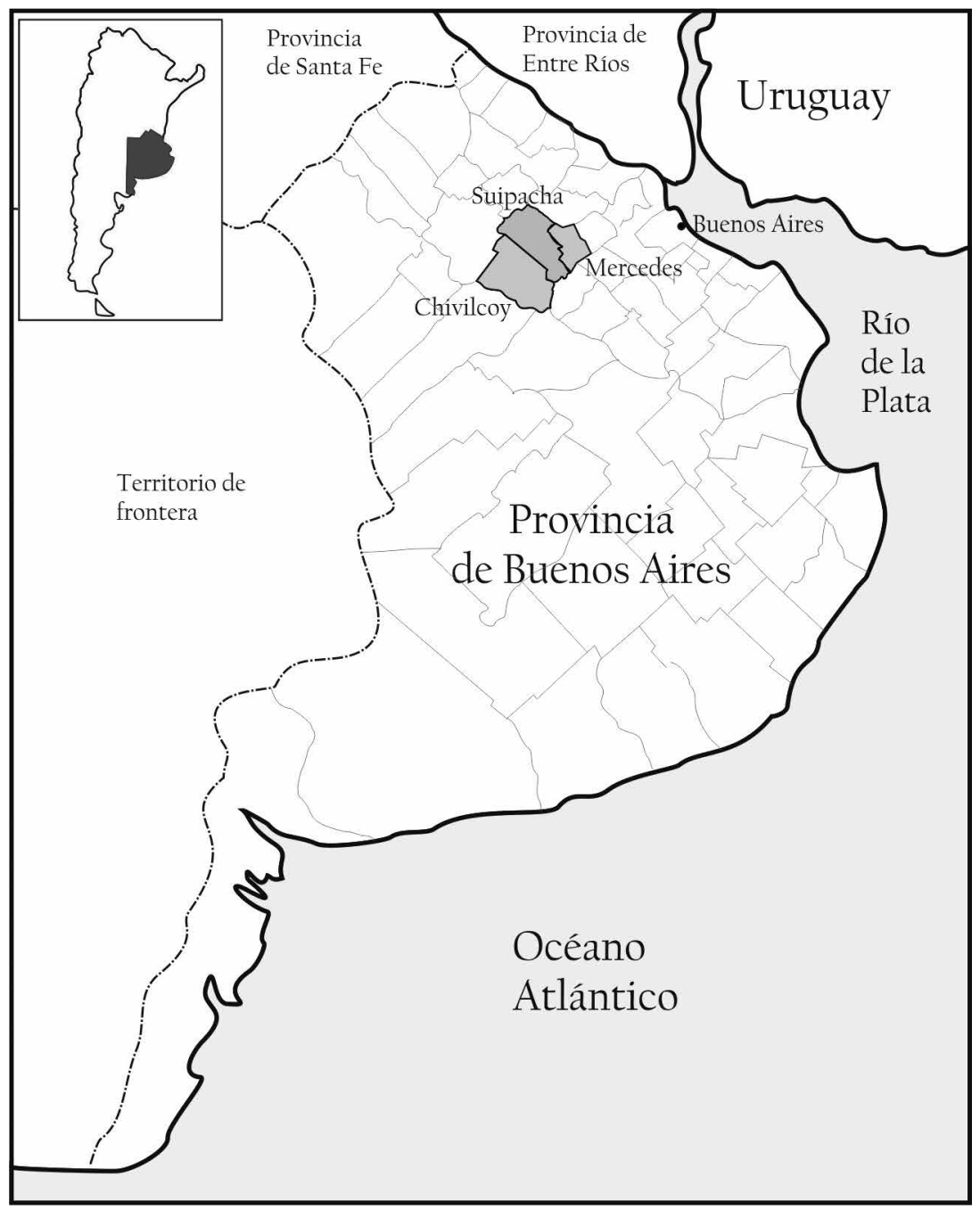

Fuente: Mapa realizado con base en Mapa de la Provincia de Buenos Aires con designación de partidos dibujado y publicado por F. Taylor, Buenos Aires, 1877.

\section{(ㄷ)(1) (3)}


ser cotejada con la correspondiente a los mismos individuos en los registros anteriores y con otra documentación que permite reflejar mejor la evolución microeconómica en esos años.

\section{La contribución directa}

Las contribuciones directas fueron implementadas en varias regiones de América Latina durante el siglo XIX para contrarrestar la dependencia creciente sobre los impuestos al comercio internacional, no obstante tuvieron una participación muy reducida en el total de ingresos públicos de cada país. Esto se debió fundamentalmente a la incapacidad estatal de controlar la recaudación debido a la guerra, la movilidad de la población, la ausencia de catastros actualizados, las deudas públicas con los contribuyentes, las declaraciones espontáneas, la depreciación de la moneda y otros (Jauregui, 2006; Santilli, 2010).

En Buenos Aires el impuesto se creó por ley del 17 de diciembre de 1821 durante la administración de Martín Rodríguez; su propósito fue gravar los capitales para aumentar el ingreso fiscal procurando no depender por entero de las rentas aduaneras. La carga imponía contribuciones anuales sobre el capital en giro, las fábricas, las haciendas, las labranzas y "otros" rubros -fundamentalmente tierra-. Fueron exceptuados de pagar el impuesto los individuos casados con capitales menores a \$m/c 2000 ( $\$$ moneda constante) y los solteros con capitales menores a $\$ \mathrm{~m} / \mathrm{c} 1000$. La modalidad de valuación consistía en la declaración del contribuyente que, en caso de duda, era corroborada por un perito. En caso de ocultamiento se estipulaba una multa. La modalidad de cobro fue trimestral y en moneda corriente. En términos generales, la declaración espontanea y la devaluación del papel moneda con-

afectaba a uno de cada cuatro o cinco varones adultos, quienes estaban potencialmente beneficiados por el decreto de excepción. Los inconvenientes señalados inciden fuertemente en la representatividad de la fuente para expresar la riqueza del partido. No obstante, esta ofrece información nominal muy rica que puede ser cotejada con la correspondiente a los mismos individuos en los registros anteriores y con otra documentación que permite reflejar mejor la evolución microeconómica en esos años. 
dicionó los resultados del impuesto que terminó teniendo muy poco éxito en materia de recaudación. ${ }^{4}$

A fines de 1838 Buenos Aires se encontraba en una crisis financiera producto del bloqueo francés y debido a ello los esfuerzos por mejorar la recaudación crecieron. Producto de ello, el 12 de abril de 1839 se dictó la nueva ley de contribución directa que se proponía una recaudación más eficaz. Así se suprimieron las exenciones a los más pobres y se incluyeron las tierras dadas en enfiteusis. Por otra parte, la responsabilidad de recaudar quedó bajo la tutela de los jueces de paz y los alcaldes suprimiéndose la declaración espontánea. Si bien los ajustes no evitaron el fraude, este disminuyó considerablemente. En 1841, luego de la coyuntura más álgida que atravesó el rosismo, se decretó la exención del pago de la contribución directa para los individuos que se mantuvieron adeptos al sistema y para los que integraban el ejército de línea y milicia (Estévez, 1960; Gelman y Santilli, 2006; Santilli, 2010).

Con la caída de Rosas, el 19 de octubre de 1852 se decretó dejar sin efecto las excepciones al pago de la contribución directa de 1841 y a partir del año siguiente se modificó el impuesto que comenzaría a gravar sólo la propiedad inmueble. Finalmente, el 27 de octubre de 1855 se promulgó la nueva ley de contribución directa. Según sus términos, las fincas y propiedades particulares pagarían anualmente $2 \%$ de su valor, eximiéndose las que no excedieran los $20000 \$ \mathrm{~m} / \mathrm{c}$. Estas últimas tenían que estar habitadas por sus dueños y estos no podían tener capital ni generar renta alguna. Los capitales se regulaban en los juzgados de paz por intermedio de una "comisión reguladora de los capitales" integrada por el juez de paz y dos propietarios nombrados por el gobierno. Los contribuyentes tenían un plazo de 30 días para pagar aunque podían reclamar sus regulaciones. En caso de no cumplir, se les pautaba $20 \%$ de aumento. ${ }^{5}$

Sumado a los cambios señalados en esta ley, a partir de 1856 se observa un cambio notable en la tendencia de las recaudaciones por contribución directa, la estabilidad de la moneda redujo las ventajas que, producto

${ }^{4}$ Las mejoras del capital en tierras o en las construcciones eran difíciles de valuar y en la práctica no se indicaban, así la tasa era única y se imponía respecto de la extensión. En el caso de las actividades urbanas, la contribución cayó sobre el valor del inmueble más que sobre los beneficios de la actividad desarrollada. Por otra parte, con la depreciación del papel moneda y al no haber indexación de los capitales, las demoras en el pago de la contribución directa fueron corrientes. Irigoin (2006, pp. 47-77).

${ }^{5}$ Ley de Contribución Directa del 27 de octubre de 1856.

\section{()(1) $(9$}


de la inflación, tenían los contribuyentes y esto desestimuló la evasión. A partir de mediados de 1850 la recaudación aumentó y los contribuyentes que pagaron en término aumentaron (Irigoin, 2006, p. 60). Aun así sobrevivían problemas, sobre todo respecto de las tasaciones puesto que el juez de paz era vecino de los contribuyentes y esto limitaba fuertemente su margen de maniobra. El gobierno lo sabía e intentó modificar el sistema en varias oportunidades, al igual que aumentar el porcentaje deducido sobre el valor de las propiedades, sin embargo la Sala de Representantes se negó. En la década de los sesenta, la legislatura accedió finalmente a modificar algunas cuestiones, en 1861 aumentó la tasa a 3\% y en 1863 decretó un mecanismo nuevo para la valuación y cobro de la contribución (Irigoin, 2006, p. 63).

En los casos donde las municipalidades funcionaban, la valuación se efectuaba allí y, además, se creó el Registro Catastral de 1864 que permitió conocer y controlar mejor el número y extensión de las propiedades. En este catastro se representaron por primera vez los ejidos.

\section{Marco general del periodo en estudio}

Durante la primera mitad del siglo xIx las pequeñas y medianas explotaciones familiares (con derechos de propiedad variados), que habían tenido un peso predominante a fines de la etapa colonial, prevalecieron en varios lugares de la campaña a pesar de la extensión de la gran propiedad rural. ${ }^{6}$ Simultáneamente, y a medida que se expandía la frontera sobre las sociedades nativas, se producía el crecimiento de un sector de grandes propietarios vinculados a la actividad ganadera. Dicho sector accedió a la tierra mediante diferentes sistemas legales que incluyeron donaciones condicionadas e incondicionadas, enfiteusis, premios, arrendamiento y ventas. ${ }^{7} Y$ concentró también ganado que, hasta mediados del siglo xIx, constituía la inversión más importante de una estancia tipo (Amaral, 1998). Pero la concentración citada no se correspondió de igual modo con los ingresos debido a la escasez de mano de obra dependiente y al fracaso de los sistemas coercitivos de tra-

${ }^{6}$ Véase el desarrollo del proceso en Miguez (2008).

${ }^{7}$ No obstante, no todos los sistemas provocaron el mismo grado de concentración y existen fuertes variabilidades regionales como excepciones en las cuales la gran propiedad no fue predominante. Infesta (2003); Valencia (2005).

\section{(1) (1)}


bajo (Gelman y Santilli, 2013, p. 661). Por otra parte, la pervivencia de una "economía moral" imponía ciertos límites a las bases del desarrollo capitalista (Fradkin, 1997, pp. 141-156). Por último, si bien la desigualdad en la distribución de la riqueza fue muy importante, los mecanismos de la herencia y un temprano mercado de tierras provocaron también parcelaciones progresivas y recambio poblacional (Banzato, Barcos y D’Agostino, 2013, pp. 19-64).

Como adelantamos en la introducción, el periodo 1839-1867 se caracterizó por un fuerte crecimiento económico a pesar de los conflictos políticos. El motor de la expansión fueron las exportaciones - primero vacunas (cuero y derivados) y luego ovinas (lana) - que a partir de la segunda mitad del xIX alcanzan cifras inéditas (Rosal y Schmit 2004; Sabato, 1989). Dicha expansión se fue consolidando luego de la unificación nacional aunque no estuvo exenta de crisis coyunturales desde muy temprano (Cortés, 1989).

Junto a la expansión de la economía citada, desde 1854 se había puesto en práctica un conjunto de dispositivos de ordenamiento legal que incluyeron la privatización de la tierra, la formación de catastros actualizados, la creación de las municipalidades y las reformas impositivas que fueron destrabando ciertos límites al desarrollo sostenido de la producción (Barsky y Djenderdjian, 2003; Garavaglia y Gautreau, 2011). Pero al mismo tiempo se producía el retroceso de la frontera, primero por el enfrentamiento entre Buenos Aires y la Confederación y la ruptura de varios acuerdos con los indígenas, luego por la disminución de efectivos en las zonas más peligrosas al inicio de la guerra del Paraguay (Ratto, 2006, pp. 13-33). La cuestión fronteriza delimitó relativamente el espacio de crecimiento horizontal de esos años y fue una de las causas que incidieron en el alza constante de los precios de la tierra. ${ }^{8}$

Jorge Gelman y Daniel Santilli (2006, 2011 y 2013) vienen trabajando la temática del crecimiento económico y la distribución de la riqueza a partir del estudio de la contribución directa. Un aspecto de esta cuestión se relaciona de modo directo con el acceso y distribución de la tierra. En sus investigaciones indican que el incremento de los valores de la propiedad inmueble en moneda constante fue notable entre 1855 y 1867, el incremento alcanzó una tasa anual de $13.1 \%$, duplicando la tasa del intervalo $1839-1855$ que fue de $6.5 \%$. El número de propietarios se incrementó en todo el periodo a un ritmo anual de $2.8 \%$, crecimiento mucho más modesto que el capital. En este senti-

\footnotetext{
${ }^{8}$ Se multiplican por diez o doce en moneda constante durante el lapso 1939-1870. Véase Gelman y Santilli (2013, pp. 659-684).
}

\section{()(1) $(9$}


do, los propietarios eran más pero eran, sobre todo, cada vez más ricos. Paralelamente al proceso señalado, se desarrolló una inequidad creciente porque el ritmo del acceso a la propiedad, aun creciendo regularmente, fue menor al de la población (4.3\%).

Entre el inicio y el final del periodo analizado el índice general Gini subió en toda la provincia, no tanto entre propietarios como en relación con las unidades censales (UC), cuestión que muestra una creciente desigualdad en el reparto de la tierra. El incremento fue constante, aunque más pronunciado en el segundo periodo; si en la primera etapa se incrementó en casi tres puntos, en la segunda lo hizo en más de cinco (Gelman y Santilli, 2013, p. 671). En la región oeste, donde este índice fue siempre igual o menor al del total provincial, durante el lapso estudiado también subió, incluso más que en toda la provincia y tanto entre propietarios como entre UC. ${ }^{9}$ Si dividimos por subperiodos, observamos que en el oeste el Gini entre propietarios también aumentó, más en el segundo periodo que en el primero; sin embargo, la desigualdad general no aumentó más que un punto.

En la región que conformaba la Guardia de Luján, los datos generales muestran la misma tendencia que toda la provincia de Buenos Aires. Entre 1839 y 1867 el Gini entre propietarios y entre Uc subió cuatro y diez puntos respectivamente. Al igual que en el conjunto del oeste, fue durante el primer subperiodo cuando se generó el alza del Gini entre Uc. Entre los propietarios el proceso fue inverso, el Gini disminuyó en el primer periodo y aumentó cinco puntos entre 1855 y 1867. Esto significa que entre 1839 y 1855 la desigualdad general creció, pero la distribución de la riqueza entre propietarios mejoró, mientras que en el segundo lapso la desigualdad general no creció, pero la distribución de la riqueza entre los que algo tenían se hizo menos equitativa.

El aumento de la desigualdad general durante el primer subperiodo se relacionaría con el proceso de crecimiento de la población de esos años. Pero en el lapso siguiente la cuestión es más compleja, la Guardia de Luján ya conformaba tres partidos que tuvieron un desarrollo diferente. Mercedes

${ }^{9}$ La bibliografía ha vinculado los menores índices de desigualdad de algunos partidos con el proceso de crecimiento de los pueblos. En 1869, 33.7\% de los habitantes del oeste vivía en poblados y los partidos estudiados aquí superaban ampliamente este porcentaje. En Mercedes habitaba 50\% del total y en Chivilcoy $44 \%$. Gelman y Santilli (2011, p. 188)

\section{(1) (1)}


Cuadro 1. Tasas de crecimiento, 1839-1867

\begin{tabular}{ccccccc} 
& \multicolumn{2}{c}{ Población } & \multicolumn{2}{c}{ Propietarios } & \multicolumn{2}{c}{ Capitales } \\
Intervalos & Buenos Aires & Oeste & Buenos Aires & Oeste & Buenos Aires & Oeste \\
& & & & & & \\
$1839-1855$ & 4.6 & 6.3 & 2.8 & 1.8 & 6.5 & - \\
$1855-1867$ & 4.0 & 3.9 & 2.8 & 4.9 & 13.1 & - \\
$1839-1867$ & 4.3 & 5.1 & 2.8 & 3.1 & 9.3 & -
\end{tabular}

Nota: cotización \$F de los años 1838, 1854, 1866.

Fuente: Gelman, J. y Santilli, D. (2013).

Cuadro 2. Gini, 1839-1867

\begin{tabular}{|c|c|c|c|c|c|c|}
\hline \multirow[b]{2}{*}{ Años } & \multicolumn{2}{|c|}{ Buenos Aires } & \multicolumn{2}{|c|}{ Oeste } & \multicolumn{2}{|c|}{$\begin{array}{c}\text { Mercedes, Suipacha } \\
\text { y Chivilcoy }\end{array}$} \\
\hline & Propietario & $U C$ & Propietario & $U C$ & Propietario & $U C$ \\
\hline 1838 & 0.66 & 0.88 & 0.57 & 0.81 & 0.56 & 0.81 \\
\hline 1855 & 0.65 & 0.91 & 0.58 & 0.91 & 0.55 & 0.91 \\
\hline 1867 & 0.67 & 0.96 & 0.60 & 0.92 & 0.60 & 0.91 \\
\hline
\end{tabular}

Fuentes: Gelman, J. y Santilli, D. (2013) para Buenos Aires y el oeste. Contribución directa de Mercedes, Suipacha y Chivilcoy. Años 1839,1855 y 1867.

y Suipacha detuvieron su crecimiento poblacional abruptamente mientras que Chivilcoy creció a una tasa de $5.9 \%$ anual.

En cuanto a la evolución de la desigualdad en la propiedad de la tierra, Gelman y Santilli $(2006,2013)$ demostraron que en el primer laspso $10 \%$ de los propietarios más ricos mantuvo relativamente el mismo porcentaje de riqueza y se incrementó el peso de los propietarios más humildes. Mientras que entre 1855 y 1867 se generó un proceso de acumulación más destacado en los estratos superiores, sobre todo del 1\% más rico. Los mayores perjudicados fueron los escalones intermedios, más cerca de los ricos que de los pobres. Veamos que sucedía en el partido de la Guardia de Luján

Entre 1839 y 1855 no hubo muchos cambios, la mayoría de los deciles se mantuvieron iguales bajando un poco el porcentaje de los más ricos y subiendo el de los más pobres. En el segundo lapso subió mucho el porcentaje

\section{(1)(1) $(9$}


de retención de riqueza de los más ricos, los estratos intermedios bajaron y los pobres se mantuvieron. Es decir, en términos generales la evolución es similar a lo que muestra la bibliografía para toda la provincia.

El proceso general descrito, no obstante, oculta variabilidades muy marcadas entre los partidos; tampoco describe cómo se desarrolló esta evolución ni por qué, por eso en el siguiente apartado analizaremos el tema haciendo hincapié en las diferencias e incorporando el tema de la movilidad social.

\section{CRECIMIENTO ECONÓMICO Y ACCESO A LA TIERRA EN MERCEDES Y CHIVILCOY}

Como puntualizamos anteriormente, el oeste tuvo, junto con el Sur II, las tasas de crecimiento poblacional más importantes de Buenos Aires. Dicho crecimiento fue importantísimo entre 1838 y 1854 (6.3\%) y disminuyó casi a la mitad entre 1854 y 1869 (3.9\%). No obstante y aun disminuyendo, se mantuvo en el promedio provincial. ${ }^{10}$ Durante la primera etapa la Guardia de Luján acompañó e incluso superó la tendencia del oeste, luego fue adquiriendo otras particularidades: en Mercedes y Suipacha la tasa de crecimiento poblacional apenas creció mientras que Chivilcoy superó ampliamente el crecimiento del oeste.

Durante el primer intervalo, la diferencia entre las tasas de crecimiento de la población y los propietarios fue muy importante mientras que en el segundo intervalo tanto Mercedes como Chivilcoy aumentaron su tasa anual de propietarios por encima de la de población. Mercedes es un caso notable, con una población que apenas creció, su tasa de propietarios se elevó mucho (6.5\%). Esto implicó también un aumento de la proporción de propietarios sobre el total de las uc que pasó de $16.9 \%$ a 23.7 por ciento. ${ }^{11}$

¿Qué sucedió con los montos? Para todo el periodo, estos crecieron a una tasa anual de $11.4 \%$, bastante más que en toda la provincia (9.3\%). Entre 1839 y 1855 la Guardia de Luján aumentó sus montos a 8.8\% anual. Entre 1855 y 1867 Mercedes y Suipacha lo hicieron a $12.8 \%$ anual y Chivilcoy a $24 \%$. Los montos promedio entre propietarios subieron de \$f 2412 a \$f 5207 en Mer-

\footnotetext{
10 Todas las zonas de Buenos Aires, salvo el Sur II, mantuvieron o disminuyeron sus tasas de crecimiento durante el intervalo 1855-1869. Gelman (2011).

${ }^{11}$ Suipacha (9.6\%), Mercedes (26.6\%).
}

\section{()(1) $(9$}




\section{Gráfica 1. Guardia de Luján}

Acumulación de cuotas de contribución directa por decil

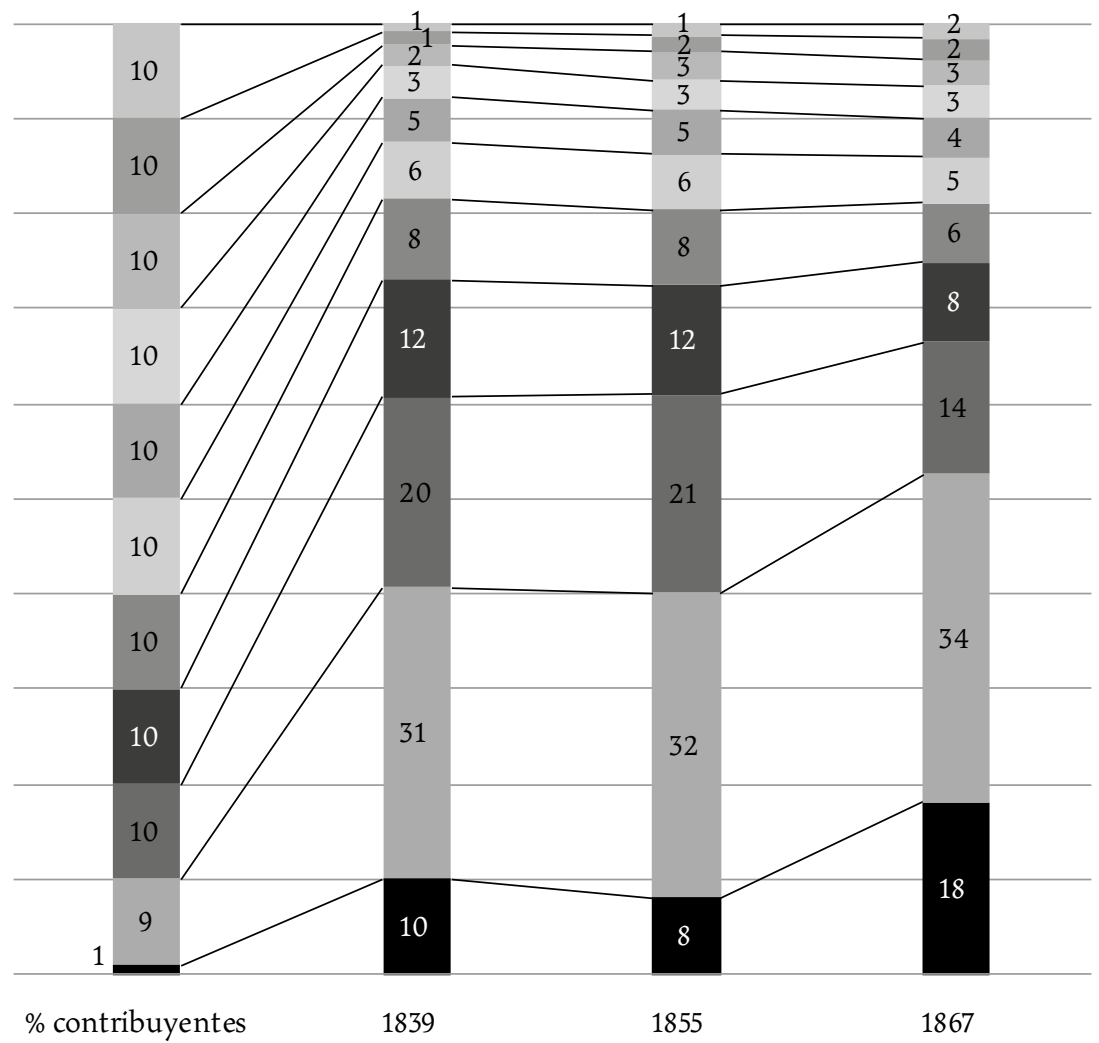

Fuente: Registros de contribución directa de los partidos de Mercedes, Suipacha y Chivilcoy. AgN, Sala III. Argentina.

cedes y Suipacha y de \$f 927 a \$f 4844 en Chivilcoy. En este último partido el crecimiento es impresionante. Como veremos en el apartado siguiente, el alza del precio de la tierra es el principal dato que influyó en el aumento de los montos. No obstante, no puede obviarse que ese crecimiento también tuvo que ver con la adquisición de nuevas propiedades rurales y urbanas o la clarificaron de derechos de actuales, cuestión que implicó el pago del gravamen.

\section{()(1) $(3$}




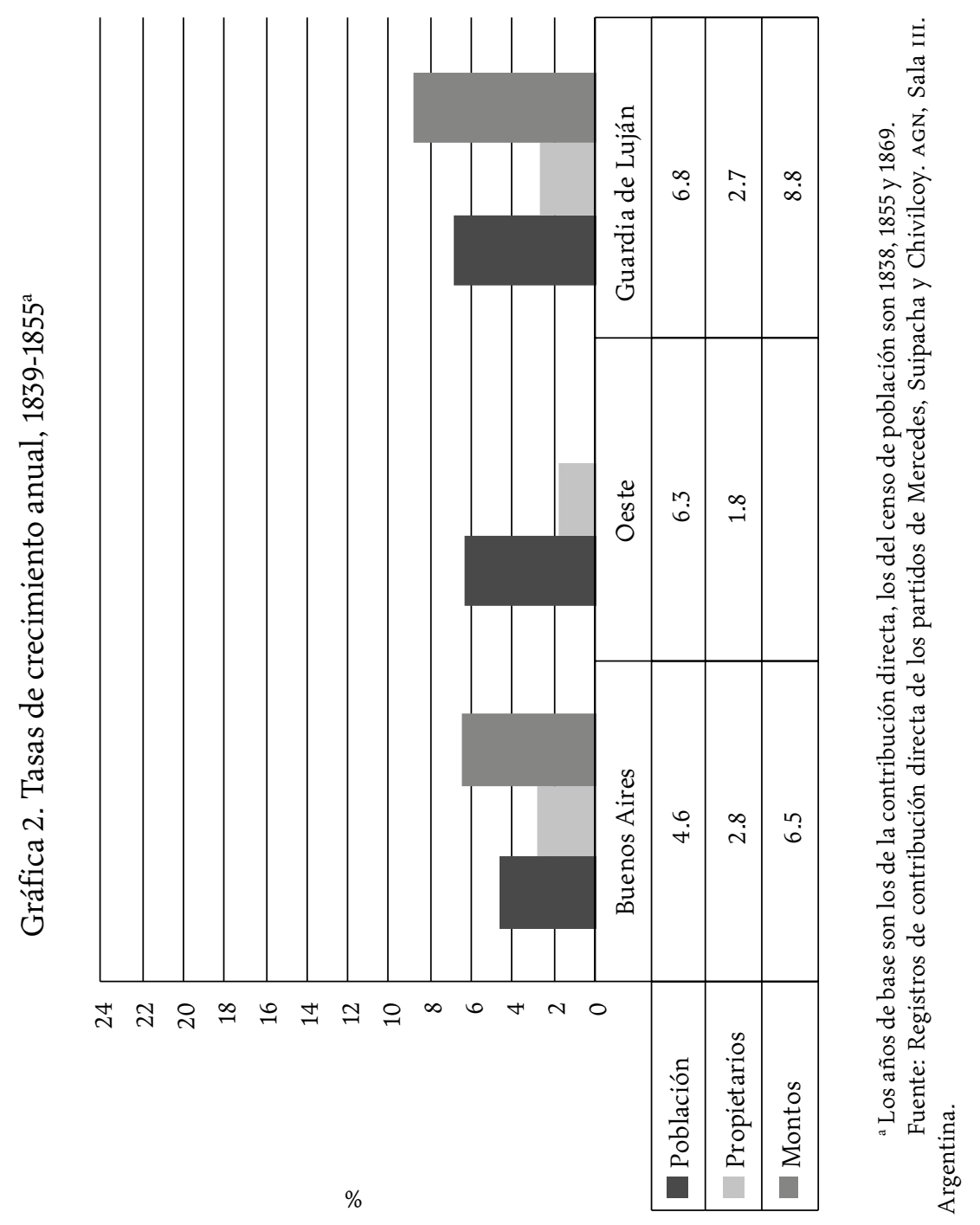

(C) (1) 


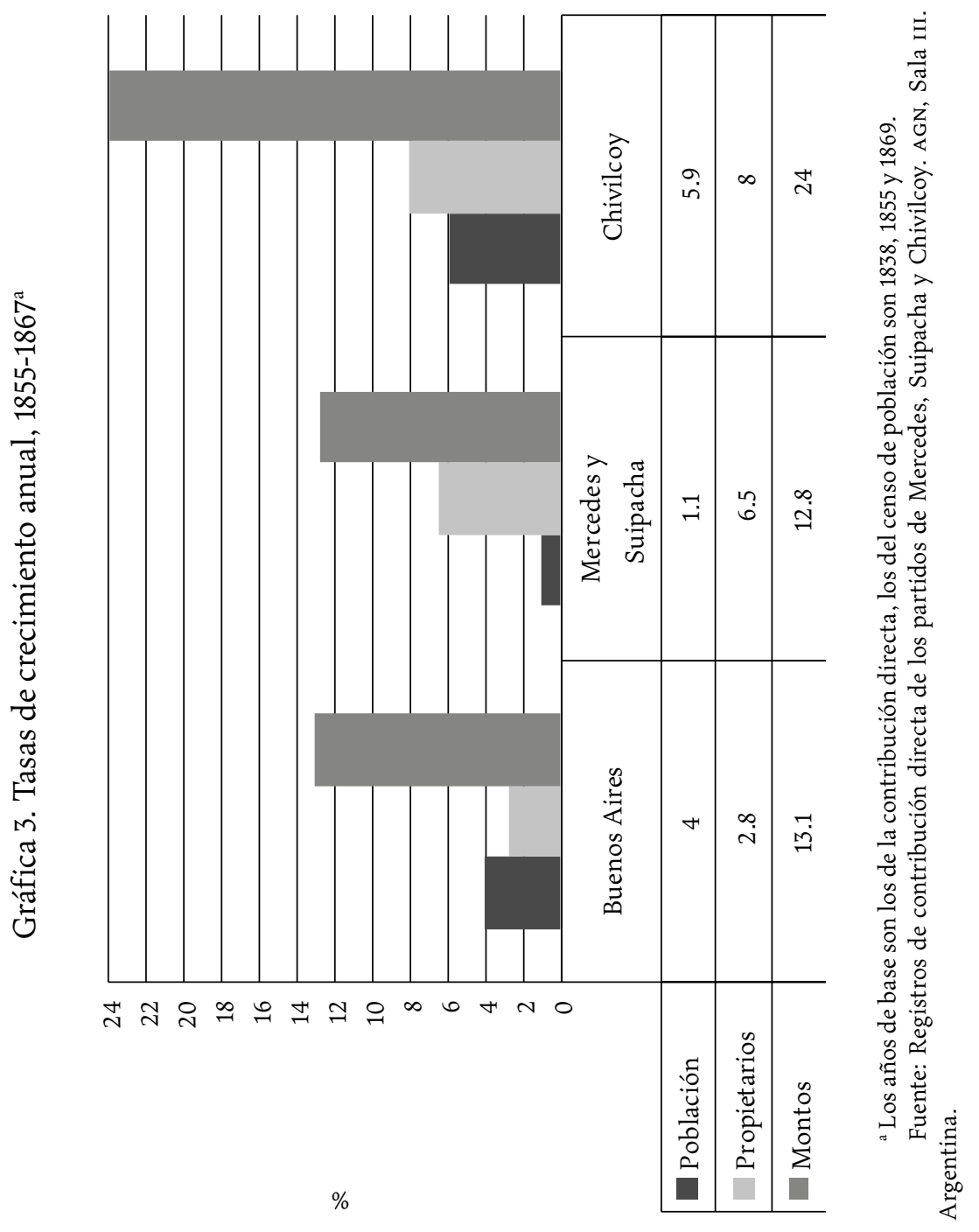

(c) (1) 
Primer intervalo, 1839-1855

A inicios de la década de 1830 ya no había tierra pública de estancia disponible en Mercedes por fuera de algunos sobrantes que recién se vendieron con la ley de 1857. Con el fraccionamiento y venta de los terrenos otorgados a fines del siglo XVIII y principios del xIX se generó un temprano mercado de tierras privadas en la zona, a este volumen se sumó otro que había sido dado en enfiteusis pero que pasó del usufructo a la propiedad entre 1836 y 1838 , momento en el cual el gobierno de Juan Manuel de Rosas autorizó a vender 1500 leguas al interior del Salado. ${ }^{12}$ La mayoría de los enfiteutas compraron. A partir de 1840 no se registraron más trámites con tierras públicas aunque continuaron las negociaciones de derechos y con terrenos privados (Infesta y Valencia, 1987, pp. 177-213). Exponemos estos datos porque permiten dar cuenta de que el crecimiento fabuloso de la población de este periodo no se correspondió con una oferta de tierras nuevas y la existente estaba ya en manos privadas casi en su totalidad. Quienes querían acceder al factor debían esperar a heredar, arrendar, fraccionar entre los miembros de su UC o comprar en el mercado de tierras privado o de transferencias.

En cuanto a la tierra pública del ejido, el poblamiento más importante se había realizado mediante donaciones entre 1813-1838. Migrantes y antiguas familias del interior del exvirreinato se poblaron allí y generaron nuevas Uc. En los años rosistas la comisión de solares del pueblo siguió donando tierra, por tanto estas parcelas constituían aún una posibilidad para que los pobladores se asentaran aunque las unidades otorgadas no superaban las siete hectáreas (quintas) o 54 ha (chacras). ${ }^{13}$ Muchos de estos ejidatarios no figuran en los registros de la década de los cuarenta e inicios de la de los cincuenta, debido a los decretos de exención, pero los ejidatarios que no fueron exonerados y los extranjeros sí. ${ }^{14}$ Más allá de esto, lo importante consiste en que el acceso a la propiedad en el ejido permitió a los sectores más pobres acceder a la tierra y por eso prevalecen numéricamente en los registros de contribución directa de la primera etapa.

12 Mediante mercedes reales, moderada composición y donaciones.

${ }^{13}$ El límite estaba dado por ley, los casos concretos muestran que las parcelas se anexaban para constituir unidades productivas mayores. Barcos (2013).

${ }^{14}$ Se establecieron exenciones para los individuos "que se mantuvieron fieles al régimen” en la coyuntura política más complicada del rosismo. En 1841 fueron también exceptuados de pagar el impuesto todos los ciudadanos en armas. Barcos (2012, pp. 1-28).

\section{()(1) $(9$}


Como se pudo demostrar a través de los expedientes de tierras, duplicados de mensura y escrituras (Barcos, 2013), estos pequeñísimos propietarios eran muchos más de los que registra la fuente impositiva. Si comparamos los registros de 1850 con los de 1855 , observamos un fuerte crecimiento en el número de propietarios que obedeció tanto a la reactivación de la política de donaciones en el ejido de Mercedes luego del Sitio a Buenos Aires como a la incorporación de los pobladores que habían sido exonerados de pagar el impuesto.

En Suipacha el primer modo de acceder a la tierra había sido la enfiteusis, muchas de estas extensiones se volvieron a negociar posteriormente, cuestión que generó cierto movimiento de titulares. Chivilcoy también se fue poblando de modo más acelerado con la implementación de la enfiteusis y para la década de los cuarenta se avanzó más decididamente sobre tierras nuevas. Por ejemplo, de los 89 propietarios de 1845 que sabemos que se ubicaban en esta zona por los duplicados de mensura, más de $90 \%$ no estaba registrado en 1839. De esta manera es factible plantear, sin dejar de observar el subregistro de los años previos, que el crecimiento en el número de propietarios que llegó a computarse en 1850 obedeció en $74 \%$ a Chivilcoy. ${ }^{15}$ Seguramente muchos de ellos eran miembros de antiguas familias, no obstante, en este trabajo los tomamos como nuevos o como pobladores que recién accedían al factor.

En suma, el crecimiento de la población de esos años no vino acompañado de una oferta de tierra pública en Mercedes. Cuando existió (como en los ejidos), eran superficies muy pequeñas y sujetas a restricciones legales para escriturar. Estas cuestiones influyeron en la tasa de crecimiento de los propietarios que, si bien ya era importante en el partido y aumentó en el lapso 1850-1855 mediante mecanismos de herencia y de mercado, lo hizo por debajo de la de población. Por eso y por la presencia de tierras "libres" allende el río Salado, el proceso de incorporación de propietarios fue mayor en Chivilcoy que en Mercedes, sobre todo en el quinquenio 1845-1850 y posteriormente.

Luego de la caída de Rosas, casi la mitad de los terrenos otorgados en enfiteusis en Chivilcoy retornaron al Estado porque fracasaron las escrituraciones. Algunos perdieron sus derechos por no pagar el canon y no haber comprado mientras que otros presentaban una situación poco clara, sobre

15 Por el decreto de 1841 fueron exceptuados de pagar la contribución directa un total de 68 propietarios. AGN, Sala III, 33-6-24. Argentina.

\section{()(1) $(9$}




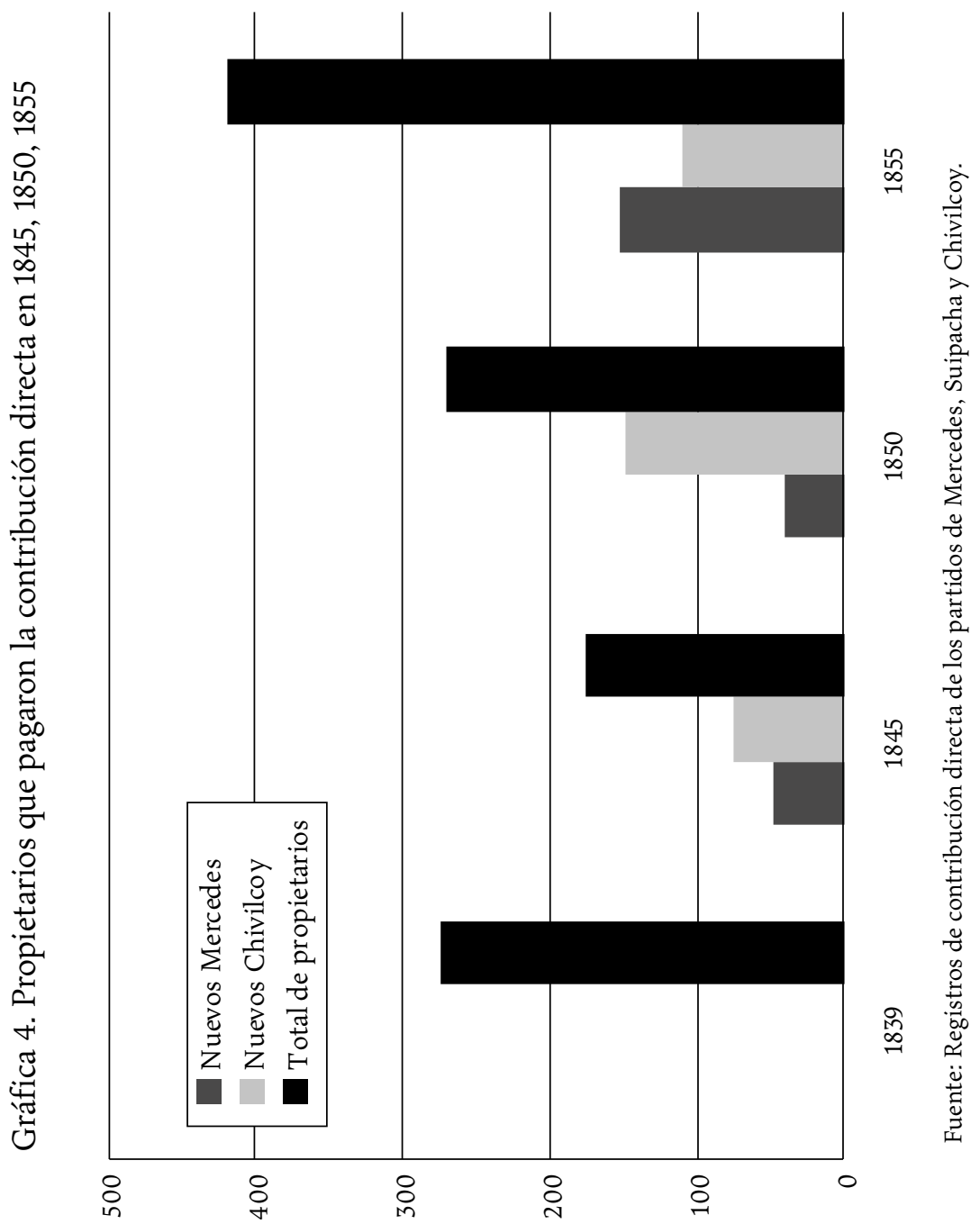

\section{(ㄷ)(1) (3)}


todo los embargados por Rosas y los adquiridos con "boletos de sangre". ${ }^{16} \mathrm{La}$ situación de inestabilidad que generó la no rectificación de los títulos sumada al poblamiento que sobre esas mismas tierras se había producido obligó al Estado a suspender por ley la enajenación de tierra hasta tanto se sancionase una ley general para este partido. En este contexto los labradores de Chivilcoy peticionaron para hacer valer sus derechos (Birabent, 1941).

\section{Segundo intervalo, 1855-1867}

El rasgo más notable del segundo intervalo es que Mercedes y Suipacha con una tasa de crecimiento de la población de $1.1 \%$ aumentaron su tasa de propietarios a 6.6\% anual. En Chivilcoy crecieron tanto la población como los propietarios pero el rasgo más notable es el importantísimo crecimiento de los montos en relación con los años anteriores.

En Mercedes y Suipacha la cantidad de propietarios aumentó fundamentalmente por los nuevos individuos que adquirieron casas y solares en el pueblo. En segundo lugar porque se incorporaron los individuos que habían comprado terrenos ejidales ( $80 \%$ de las parcelas se vendieron en 1864 y 1865) y los que habían podido escriturar mediante la ley de clarificación de derechos de $1862 .{ }^{17}$ Algunos pocos de los nuevos propietarios adquirieron campos que estaban bajo el sistema de arrendamiento y sobrantes por medio de las leyes de 1857,1864 y 1867 . El resto debió haber accedido a la propiedad mediante las compraventas y la herencia.

En Chivilcoy, el 13 de octubre de 1857 se sancionó la ley de tierras que, si bien tuvo complicaciones y vericuetos aún no estudiados en profundidad, incorporó más propietarios a los que ya estaban computados. En su ejido también se pusieron en venta los terrenos y se aplicó la ley de reconocimiento de derechos ya citada. Por último, casi 36\% del total de propiedades computadas en 1867 eran fincas urbanas. En suma, el proceso de urbanización fue una de las causas más importante del aumento en el número de propietarios como también las ventas de terrenos públicos para quintas y chacras que el

\footnotetext{
${ }^{16}$ Premios otorgados durante el periodo rosista, véase Infesta (2003).

${ }^{17}$ En Mercedes esto no implicó necesariamente un reconocimiento de los antiguos ocupantes puesto que la antigüedad se computó sobre la parcela y no sobre el poblador. Barcos (2013).
}

\section{(1) (1) $(9$}


Estado propició. Sumado a esto, los mecanismos de la herencia y el mercado de tierras completaron el proceso que dio como resultado el crecimiento notable en el número de propietarios.

El otro rasgo del periodo fue el fabuloso crecimiento de los montos, sobre todo en Chivilcoy que para 1867 "declaraba" algo más de riqueza territorial que su vecina Mercedes. ${ }^{18} \mathrm{El}$ alza del precio de la tierra ya fue advertida y en la región fue aún más acentuada. Tengamos en cuenta que en la década de los sesenta llegaba el ferrocarril del Oeste a Mercedes y Chivilcoy atravesando el "corazón del distrito lanero al occidente de la Capital" (Sabato, 1989, p. 232). Y por otra parte las innovaciones tecnológicas en la agricultura cerealera debieron haber impactado en la valorización de estos terrenos.

Sumado a esto, los propietarios aumentaron su patrimonio inmobiliario al incorporar nuevas unidades; es un dato bien común encontrar propietarios que tenían campos y/o chacras/quintas y solares en el pueblo. Si bien y como era de esperar, tanto en Mercedes como en Chivilcoy la mitad del total de riqueza provenía de campos y estancias, es importantísimo el capital que se computó en fincas urbanas, sobre todo en Mercedes donde representaban $40 \%$. El resto eran quintas y chacras que, si bien eran muy numerosas, valían mucho menos. En Suipacha el total de propiedades computadas provenía de campos.

\section{Distribución de la riqueza}

Para toda la zona que conformó la Guardia de Luján entre 1839 y 1867 la desigualdad general creció puesto que el Gini entre UC aumentó diez puntos. El aumento se generó durante el primer subperiodo y se mantuvo igual en el segundo. Así, para 1855 la región había alcanzado los niveles del conjunto de Buenos Aires (Gini 0.91) pero al interior del grupo de propietarios la distribución seguía siendo mejor (véase cuadro 1), sobre todo en Mercedes. En el cuadro 4 se observa la distribución de la riqueza por partidos.

18 Según Andreucci, desde 1858 se observa a una franja de medianos y grandes labradores que valorizaron rápidamente sus activos con el éxito de la producción triguera. Junto a ellos también crecieron los grandes propietarios como White, Terreros o Cranwell. Andreucci (2011, p. 164). 


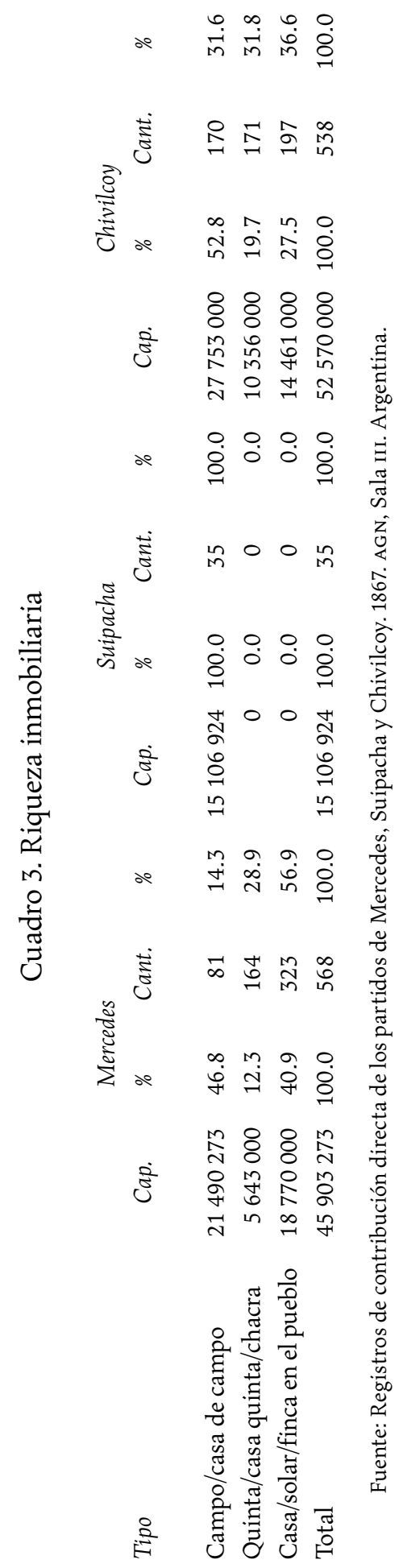

(ㄷ)(1) 


\section{Cuadro 4: Datos básicos por partido}

\begin{tabular}{lrrrr} 
& \multicolumn{1}{c}{1855} & \multicolumn{1}{c}{$\begin{array}{c}1867 \\
\text { Datos }\end{array}$} & $\begin{array}{c}1855 \\
\text { Mercedes y Suipacha }\end{array}$ & \multicolumn{2}{c}{ Chivilcoy } \\
& & & & \\
Población & 8730 & 8146 & 6001 & 14232 \\
Propietarios & 247 & 486 & 172 & 438 \\
\% de propietarios sobre población & 2.8 & 5.9 & 2.8 & 3 \\
\% de propietarios sobre total de uc & 16.9 & 29.2 & 22.9 & 21.8 \\
Capitales & 59518 & 250444 & 159423 & 2121520 \\
Gini prop. & 0.45 & 0.63 & 0.57 & 0.54 \\
Gini uc & 0.9 & 0.92 & 0.91 & 0.89 \\
20\% más rico & 52 & 72 & 65 & 61 \\
20\% más pobre & 5 & 3 & 6 & 5
\end{tabular}

Nota: de acuerdo con el padrón de 1838 y el censo de 1869 se computó un tamaño de UC de seis miembros para Mercedes y Suipacha y de ocho para Chivilcoy.

Fuente: Registros de contribución directa de los partidos de Mercedes, Suipacha y Chivilcoy. AgN, Sala III. Argentina.

Chivilcoy tenía un Gini de propietarios similar al conjunto del oeste, pero doce puntos más alto que el de su vecina. Al llegar a 1867, la situación se había invertido: la distribución de la riqueza terminó siendo mucho más desigual en Mercedes y relativamente más equitativa en Chivilcoy. Decimos relativamente porque $20 \%$ de propietarios más pobres disminuyó el porcentaje de riqueza que retenía en los dos partidos. En cuanto al 20\% más rico, en Chivilcoy casi no hubo cambios mientras que en Mercedes y Suipacha pasaron de retener $52 \%$ del total de riqueza a 72 por ciento.

Al calor de la expansión del lanar, en Mercedes y Suipacha se produjo un enriquecimiento económico importante al que se sumó un acaparamiento de riqueza inmobiliaria entre sectores ligados a esta economía pero que tenían también un fuerte posicionamiento en el comercio que esta fuente no muestra pero que pudimos detectar a través del cotejo con los registros de patentes comerciales y los préstamos del Banco Provincia de la década de 1860 (Barcos, 2013).

Como muestra la gráfica $5,1 \%$ de los propietarios más ricos acumulaba en 1867 casi el triple de riqueza de lo que el mismo porcentaje retenía en 1855.

\section{()ㅜ(1)}




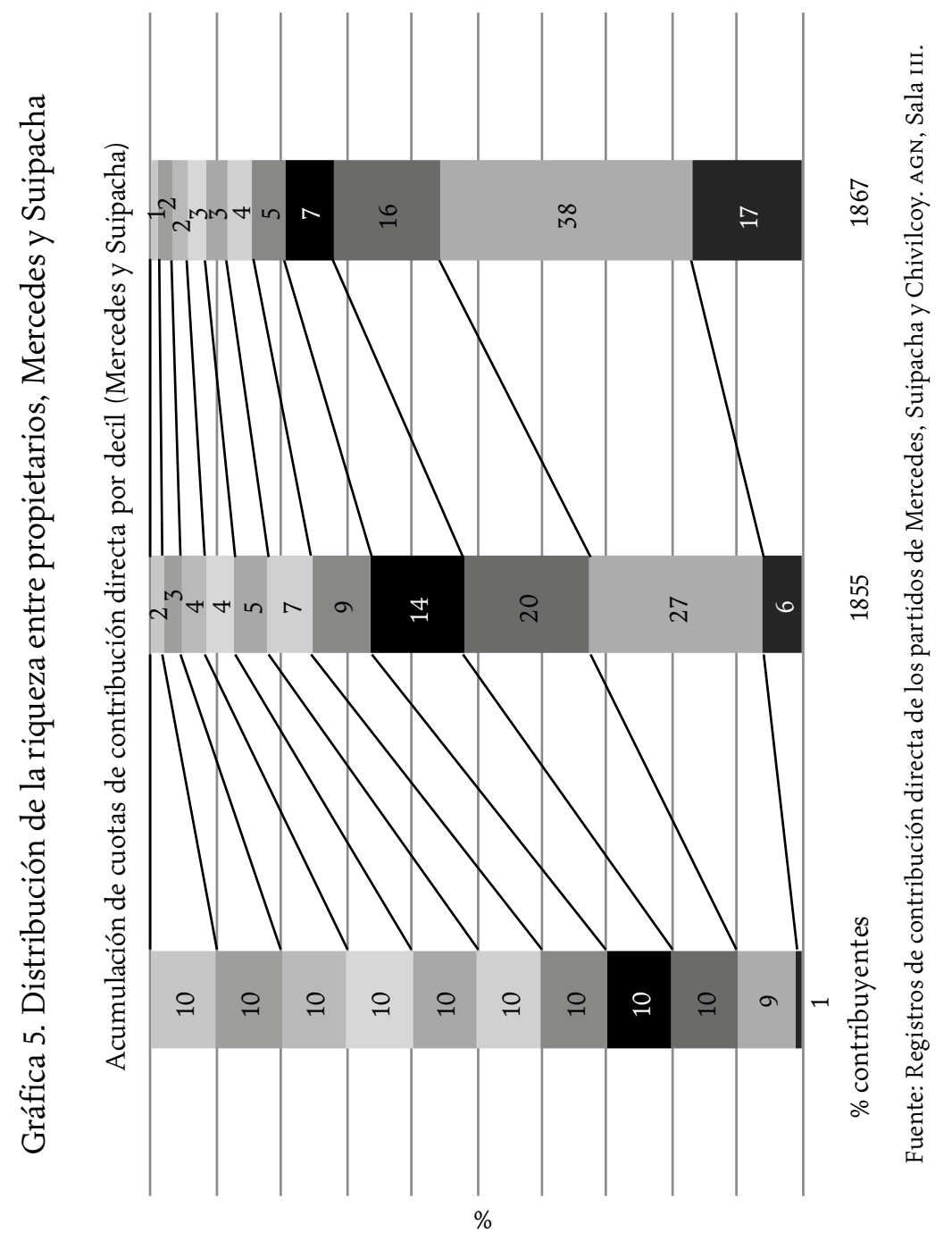

\section{(c) (1)}


Por otra parte, a partir del tercer decil todos los escalones disminuyeron su participación aunque los que más cayeron son los deciles más cercanos a los ricos. Esta evolución es la misma, aunque aquí más pronunciada, que se observa para toda la provincia.

Veamos tan sólo tres ejemplos del 1\% más rico: la testamentaria de Unzue fue el máximo contribuyente, este propietario había sido un importante hacendado y comerciante que murió en el año 1853. Sus actividades se caracterizaron por la diversificación ya que tenía estancias y quintas pero también depósitos en el banco, mercaderías, acciones y acreedores (Sabato, 1989, p. 171). En 1867 la testamentaria contribuyó sólo por el campo de Mercedes. Felipe Augusto Picot, francés, estaba también entre los máximos contribuyentes, oficiaba de rematador pero también de prestamista e incluso era corresponsal del periódico El Monitor de la Campaña del partido de Exaltación de la Cruz. Tenía un solar y una valiosa casaquinta en el pueblo. En los dos casos no habían pagado contribución directa en 1855. En cambio, la testamentaria de Pascuala Iramain de Achaval o el caso de Pablo Martínez si formaban parte de antiguas familias (exenfiteutas) de la zona, en 1867 contribuían por sus campos.

Como ya expresamos, en Chivilcoy no se produjeron cambios importantes en los estratos más altos puesto que los poderosos no retuvieron un porcentaje mayor de riqueza del que ya tenían en 1855; en cambio, los deciles siguientes aumentaron o mantuvieron su participación.

El desarrollo de la zona en estos años fue muy importante pero para este partido tenemos menos datos primarios, no obstante, otros autores han puesto de relieve el proceso de valorización de los terrenos al ritmo de la expansión cerealera. Al mismo tiempo, todo indica que los efectos de la ley de tierras de 1857 habrían permitido mitigar el peso del acaparamiento que se había operado con el sistema enfitéutico (Djenderedjian, 2008).

\section{MOVILIDAD SOCIAL EN MERCEDES Y SUIPACHA, 1839-1867}

El peso de la tierra en el conjunto de los capitales de los contribuyentes de la Guardia de Luján venía aumentando progresivamente desde 41.6\% en 1839 hasta $53.2 \%$ de 1850. En Mercedes la tierra constituía 50\% del total de la riqueza del partido pero el giro había crecido hasta constituir 25\%. Lamen-

\section{()(1) $(9$}


Gráfica 6. Distribución de la riqueza entre propietarios, Chivilcoy

Acumulación de cuotas de contribución directa por decil (Chivilcoy)

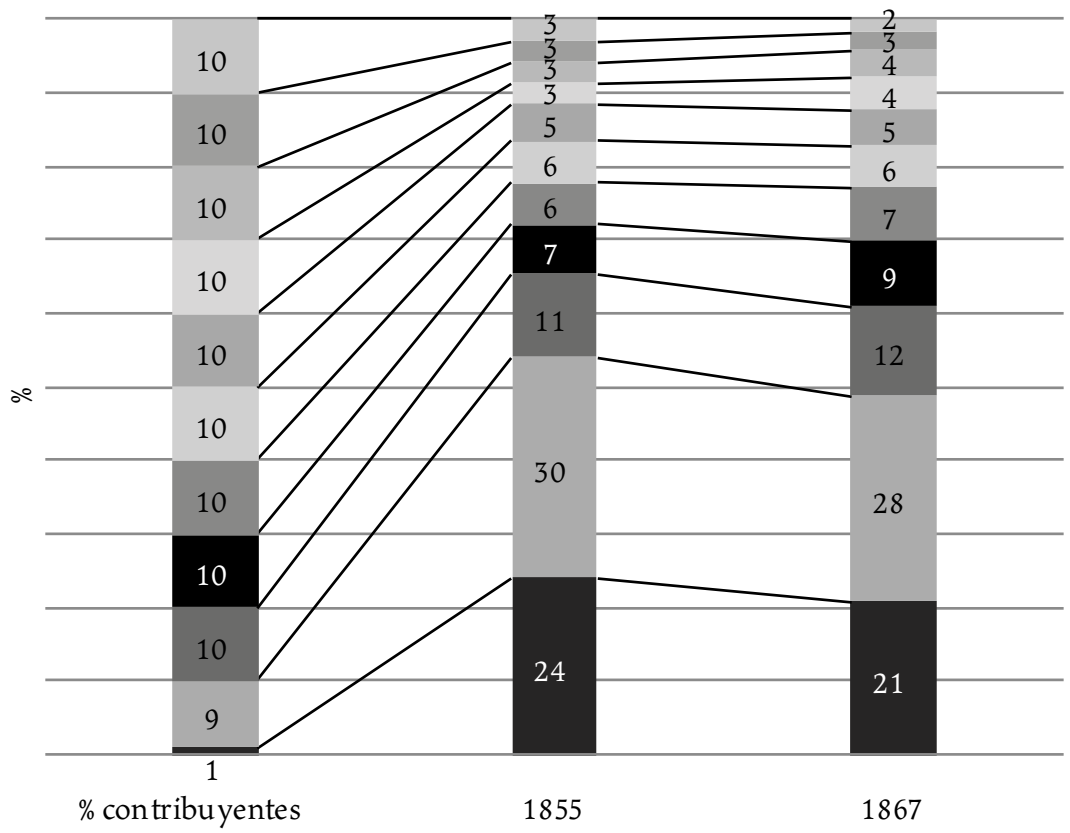
Argentina.

Fuente: Registros de contribución directa del partido de Chivilcoy. AGN, Sala III,

tablemente no podemos seguir ponderando este rubro con la fuente impositiva pero tenemos serias hipótesis que indican que el peso se mantuvo e incluso creció.

En estos once años de enriquecimiento, la recaudación producto del cobro de la contribución directa aumentó y se promovió un fortalecimiento del sector de los medianos productores con posibilidades de acumulación. Para las dos aseveraciones el crecimiento fue aún mayor que lo que refleja la fuente debido a la cantidad de potenciales tenedores de riqueza que quedó fuera del recuento por las excepciones de la época. Esta sociedad se mostró muy dinámica y se registró una fuerte movilidad ascendente, sobre todo entre los pobres y los medianos en proceso de capitalización, en cambio los 
ricos se mantuvieron en esa franja o descendieron. ${ }^{19}$ Las posibilidades que brindaba la región fueron utilizadas por los migrantes quienes a lo largo de su ciclo de vida pudieron ascender en la escala de riqueza. Estos itinerarios no estuvieron exentos de crisis y malas coyunturas que implicaron drenajes en el patrimonio de varias familias.

El quinquenio 1850-1855 fue muy complejo, puesto que se vivieron constantes conflictos políticos que pudieron haber incidido en la capacidad estatal de recaudación y/o incluso en el relajamiento del control. Recordemos que en diciembre de 1852 se inició el Sitio a Buenos Aires desde el pueblo de Mercedes. Durante el conflicto la recaudación la cobró el jefe sitiador y la cantidad de individuos que pagaron el impuesto fue muy menor en relación con los años anteriores y posteriores. Las guerras civiles también generaron pérdida de la riqueza (por ejemplo, en el registro de 1853 sobresale la disminución de los montos por ganado) y modificaciones en la composición de la población. El Registro Estadístico de 1855 daba cuenta de esto:

Una de las más notables, y que puede servir de comprobante de lo asoladoras de nuestras guerras civiles, es el numero asombroso de viudas que hay en la campaña, comparado con el de viudos, y que justamente se revela con elocuentes cifras, [...] como en la Guardia de Luján, en donde estalla otra revolución, y se ven 269 viudas y 82 viudos; [...] (Registro Estadístico de 1854, p. 35).

Luego del triunfo separatista de Buenos Aires, los problemas internos se resolvieron sólo parcialmente puesto que la conflictividad con los indígenas fue in crescendo. Más allá de esto, se tomaron tres medidas fundamentales para este tema, la contribución directa se modificó gravando sólo la tierra, se eliminaron las exacciones y se comenzaron a revisar los premios y embargos. Si comparamos los registros de Mercedes de 1850 con los de 1855 ya se observaba un crecimiento en el número de contribuyentes, cuestión que también tuvo que ver con los problemas de registro de la fuente mientras estuvieron vigentes las excepciones, y un incremento de los montos. No obstante, el salto se da claramente a mediados de la década de 1860 .

Analizaremos ahora la movilidad de los que permanecieron en Mercedes entre 1839 y 1855: fueron 54 propietarios que representan $28 \%$ del total de la base del último año. En promedio tenían un capital inicial de $941 \$$ f y

19 Seguimos la clasificación de Gelman y Santilli (2006).

\section{()(1) $(9$}


llegaron a $33361 \$$ f al final, monto $1.5 \%$ más elevado que el promedio del resto de los contribuyentes. ${ }^{20}$ La tasa de crecimiento promedio fue sólo un poco (8.2\%) más alta que la del total de la base (7.8\%). ${ }^{21}$ Sin embargo, debido a la disparidad de cada tasa individual es importante aclarar que más de $40 \%$ de estos contribuyentes creció por encima del promedio, estos últimos eran propietarios "medianos en proceso de acumulación" y, más frecuentemente, "ricos". ${ }^{22}$ Seguramente, en estos casos pesó más la adquisición de nuevas parcelas por medio de la compraventa particular y algunas inversiones que el aumento del precio de la tierra que en este lapso fue menor al periodo siguiente. Además, tengamos en cuenta que en esta zona donde la propiedad pública era casi inexistente el mercado de tierras estaba más desarrollado (Banzato et al., 2013, pp. 19-54).

Realizando las mismas cuentas para el lapso 1855-1867 observamos que ahora permanecieron casi la mitad de los propietarios de 1855, estos 116 individuos representaban $22 \%$ del total de la base del último año. Al iniciar el periodo tenían un promedio de capital de $2886 \$$ y y al final del lapso llegaron a 7219 \$f. Monto también 1.5\% más alto que el promedio del resto de los contribuyentes. ${ }^{23} \mathrm{~A}$ diferencia del periodo anterior, la tasa de crecimiento de los viejos (7.9\%) fue bastante más baja que la del conjunto (12.8\%). Es importante señalar que en este lapso la disparidad de las tasas de crecimiento individual fue mayor que en el periodo anterior, casi un cuarto de estos propietarios tuvo tasas negativas y el otro cuarto creció por encima del promedio. En un periodo donde el alza del precio de la tierra fue muy importante, es muy probable que la oferta de tierra pública, luego de las leyes de venta sumado a las transferencias -donde unos sumaban y otros restaban a su patrimonio tierras- y a la diferente valorización de las explotaciones por la incorporación de rubros más dinámicos, deben haber desempeñado un papel importante en la diversidad de situaciones que se evidencian. Volveremos sobre esto al final del trabajo. Por último, los contribuyentes que ya habían sido registrados en 1855 retenían en conjunto 33\% de la riqueza total del partido, así fueron los nuevos propietarios los que más riqueza aportaron.

\footnotetext{
$202174 \$ f$.

21 Recordamos al lector que no está incluido Chivilcoy.

22 De acuerdo con la clasificación de Gelman y Santilli (2006).

234839 \$f.
} 


\section{Los nuevos capitalistas}

Los 370 nuevos contribuyentes de 1867 contaban con un capital promedio menor (4 839\$f) que los viejos (7 219 \$f) pero eran bastante más. Al mismo tiempo, la amplia mayoría (83\%) no declaró más de 5000 \$f y reunía sólo 32\% de la nueva riqueza. Esto significa que había un pequeño porcentaje de nuevos contribuyentes mucho más ricos que el conjunto.

Casi $40 \%$ declaraba quintas en el ejido y casi todos habían escriturado entre 1863 y 1867, cuestión que apoya nuestra argumentación respecto del crecimiento en el número de propietarios del lapso 1855-1867. La amplia mayoría eran ejidatarios pero también había un porcentaje que tenía además campo (seis individuos) y solares en el pueblo (36 individuos). De los 109 contribuyentes que compraron terrenos ejidales, sólo unos pocos compraron baldíos, el resto había adquirido previamente derechos, esto explica la desaparición de varios contribuyentes que figuraban en 1855. Lo que se produce en estos casos no es una desaparición de los sectores "pequeños" y "medianos" sino un cambio de titularidad porque a partir de 1854 muchos ejidatarios vendieron sus terrenos mayormente a inmigrantes. Producto de esto, es muy probable que los labradores y familias que vendieron sus pequeñas parcelas hayan terminado integrando el elenco de asalariados que será propio de la estructura agraria de las décadas siguientes.

También había un muy importante $42 \%$ de propietarios que sólo declaraba casas en el pueblo. En este sentido, la fuerte urbanización de este pueblo agregó un nuevo elemento a la riqueza inmobiliaria. Muchas de estas casas eran negocios comerciales, panaderías, almacenes y otros. Y por último se encontraban los hacendados que constituían el 18\% restante de los propietarios. Entre ellos se ubicaban los más ricos, muchos de ellos extranjeros y que tenían sobre todo campo, pero también había otra camada que diversificaba entre casas, campos y quintas.

\section{CONCLUSIONES}

Durante los años que abarca este trabajo, la provincia de Buenos Aires experimentó un fuerte crecimiento económico al calor de la expansión agropecuaria. De acuerdo con los datos que brinda el impuesto de la contribución directa se pudo advertir tanto el crecimiento en el número de capitalistas como

\section{()(1) $(9$}


el aumento aún mayor de los montos que estos retuvieron. Paralelamente al crecimiento señalado se generó una creciente desigualdad en la distribución de la riqueza (fundamentalmente tierra pero también construcciones como estancias, quintas, chacras y solares) sobre todo porque el ritmo de acceso a la propiedad, aun creciendo regularme, fue menor al de la población. Este incremento (expresado en el índice Gini) fue constante, aunque más pronunciado entre 1855 y 1867. La región oeste, que partía de un Gini siempre menor al total provincial, tuvo, no obstante, un comportamiento diferencial: en el primer subperiodo la desigualdad general creció pero la distribución de la riqueza entre propietarios mejoró mientras que en el segundo lapso la desigualdad se mantuvo en el mismo índice pero las diferencias entre los que algo tenían se hicieron más pronunciadas (Gelman y Santilli, 2011).

Esta investigación avanzó sobre las razones que permiten explicar más detalladamente los procesos señalados y sus particularidades. Durante la primera etapa, la Guardia de Luján había acompañado e incluso superado la tendencia del oeste en cuanto al crecimiento de la población. Como dicho crecimiento no fue acompañado de uno similar en la tasa de propietarios, la desigualdad creció. Explicamos que esto se debió a dos procesos, la escasez de terrenos públicos y los límites de la expansión fronteriza puesto que aún no se había avanzado completamente sobre las tierras del actual partido de Chivilcoy. Así, quienes pudieron acceder a la propiedad lo hicieron mediante el mecanismo de la herencia, o al recibir una donación ejidal. También porque compraron derechos sobre algún terreno (o fracción) en el mercado de transferencias o realizaron alguna compraventa particular. Pero en todos los casos, salvo en las parcelas ejidales, la negociación era sobre el mismo volumen de tierra que cambiaba de manos.

En el lapso siguiente la región experimentó dos procesos diferentes, en Mercedes y Suipacha la población creció muy poco mientras que en Chivilcoy la tasa se mantuvo casi al mismo ritmo que en el periodo anterior. El caso de Mercedes y Suipacha es común a toda la región del oeste que detuvo su crecimiento para, en años posteriores, volver a crecer. En Chivilcoy donde el poblamiento había sido más tardío, entre 1855 y 1867 la población continuó aumentando al amparo del desarrollo cerealero.

Frente a estos procesos dispares, los propietarios crecieron en los dos partidos y a tasas más altas que la población. Mostramos que las causas de este crecimiento obedecieron a la compra de fracciones de terrenos públicos que recién en ese momento el Estado puso a la venta, tanto en el ámbito rural

\section{()(1) $(9$}


como en los ejidos de los pueblos. Y también por la compra de solares urbanos puesto que uno de los rasgos de estos partidos fue el fabuloso crecimiento de sus pueblos, en cada uno de ellos se ubicaba $50 \%$ del total de la población de cada partido. En el caso de Mercedes, su poblado además se había convertido en la sede comercial del oeste, no sólo llegaba el ferrocarril sino que también se había establecido una sucursal del Banco Provincia. A todos los aspectos señalados debe sumarse la parcelación, herencia y compraventa privada que terminarán por generar un mercado de tierras donde coexistían las transferencias de derechos, la oferta estatal y la privada.

Otro rasgo notable es el fabuloso crecimiento de los montos del segundo subperiodo, sobre todo en Chivilcoy. Este incremento se debió fundamentalmente al alza del precio de la tierra incentivada por la demanda que generaba una economía en expansión. Pero la valorización de los terrenos crecía no sólo por el auge del lanar, la especialización cerealera sobre nuevas tierras generaba nuevas posibilidades para este mercado que venía estando suscrito al ámbito radial de los pueblos. La llegada del ferrocarril potenciaba, además, toda esta economía al barrer con una de las limitaciones estructurales más graves del sistema de comercialización tradicional.

Todo este crecimiento se produjo en un marco en el que la desigualdad general en la distribución de la tierra aumentó a lo largo de todo el periodo. Pero, ¿qué sucedió con la distribución hacia adentro del elenco de propietarios? Observamos algo que ya habían manifestado otros autores: en la Guardia de Luján la desigualdad en el reparto de la riqueza fue mucho más importante en el segundo lapso (1855-1867) que en el primero (1839-1855). Pero detectamos nuevas variables al diferenciar los partidos y estudiarlos detalladamente, en 1855 Mercedes y Suipacha tenían un Gini menor a Chivilcoy y el peso de $20 \%$ más pobre era similar. Al finalizar el periodo la situación era totalmente distinta, Chivilcoy había disminuido su Gini y aparecía como un partido donde la distribución de la riqueza era más equitativa. ¿A qué obedecieron estos cambios?

Todo indica que los efectos de la ley de tierras de 1857 habrían permitido mitigar el peso del acaparamiento que se había operado con el sistema enfitéutico, recuérdese que una importante cantidad de hectáreas volvieron al Estado. Y además esta ley podría haber permitido el acceso a la propiedad de los sectores más bajos. No obstante, es necesario un estudio detallado sobre quiénes escrituraron y cómo se realizaron los trámites para dar una respuesta más completa. En cambio, en Mercedes, que había registrado una

\section{()(1) $(9$}


fuerte movilidad ascendente durante el primer lapso, sobre todo entre los "pobres" y los "medianos" en proceso de capitalización, entre 1855 y 1867 experimentó una concentración importantísima de los sectores "poderosos" en detrimento de los restantes. Sin embargo, el proceso es aún más complejo porque al mismo tiempo que se generaba la situación descrita ingresaba una cantidad importante de nuevos propietarios con capitales dentro de los deciles más bajos

Muchos de los nuevos propietarios eran extranjeros que se ubicaron en el ejido como agricultores -sobre todo los italianos y en el ámbito rural al amparo del desarrollo lanar-. También se establecieron como comerciantes en el abanico de actividades que desarrollaban en el pueblo. Gran parte de las casas que se computaron en los registros de contribución directa eran negocios comerciales (Barcos, 2013). Paralelamente, entre los antiguos pobladores se producían otros itinerarios, varios de los pequeños propietarios vendieron sus pequeñas parcelas: en trabajos anteriores observamos un aumento en el número de transferencias a partir de mediados de la década de 1850 y posteriormente. Estos movimientos acompañaron la oferta estatal y los precios por hectárea que se manejaron tuvieron una gran dispersión pero estuvieron siempre por encima que los de la tierra pública. Esto podría haber sido un negocio para los pequeños labradores en algunos casos y en otros podría haber ocasionando el descenso de posición en la escala de riqueza.

En suma, el elenco propietario que se generó estuvo integrado por una mayoría que se ubicaba en los deciles más bajos y un puñado de ricos que retuvieron la mayoría de la tierra y propiedades de la zona. Estos ricos "muy ricos" diversificaron su patrimonio en estancias, quintas, chacras, casas y negocios comerciales poniendo al descubierto un desarrollo complejo y mucho más diverso en el que nativos e inmigrantes confluyeron.

\section{LISTA DE REFERENCIAS}

Amaral, S. (1998). The rise of capitalism on the Pampas. Cambridge: Cambridge University Press.

Andreucci, B. (2011). Labradores de frontera. La Guardia de Luján y Chivilcoy, 1780-1860. Rosario: Prohistoria.

Banzato, G., Barcos, M. F. y D’Agostino, V. (2013). Problemas, métodos y abordajes teóricos en torno al mercado de tierras. La campaña bonaerense entre los siglos

\section{()(1) $(9$}


XVIII y XIX. En G. Banzato (ed.), Tierras rurales. Políticas, transacciones y mercados durante el siglo XIX en Argentina (pp. 14-71). Rosario: Prohistoria.

Barcos, M. F. (2011), La venta de tierras ejidales a la luz del proceso de construcción del Estado en Buenos Aires. En Juan Carlos Garavaglia y Pierre Gautreau (eds.), Mensurar la tierra, controlar el territorio. América Latina, siglos XVIII y XIX (pp. 295-325). Rosario: Prohistoria.

Barcos, M. F. (enero-junio, 2012). Algunas reflexiones en torno al crecimiento económico, la distribución de la riqueza y la posesión de la tierra en la Guardia de Luján durante el segundo gobierno de Rosas. Quinto Sol, 16(1), 1-28.

Barcos, M. F. (2013). Pueblos y ejidos de la campaña bonaerense. Una historia sociojurídica de los derechos de propiedad y la conformación de un partido: Mercedes, 1780-1870. Rosario: Prohistoria

Barsky, O. y Djenderdjian, J. (2003). Historia del capitalismo agrario pampeano. T. 1: La expansión ganadera hasta 1895. Buenos Aires: Siglo XXI Editores.

Birabent, M. (1941). Chivilcoy la región y las chacras. La Plata: AHPBA.

Cortés Conde, R. (1989) Dinero, deuda y crisis: evolución fiscal y monetaria en la Argentina, 1862-1890. Buenos Aires: Sudamericana.

Djenderedjian, J. (2008). La agricultura pampeana en la primera mitad del siglo XIX. En O. Barsky (dir.), Historia del capitalismo agrario pampeano (T. IV). Buenos Aires: Universidad de Belgrano/Siglo XXI.

Estévez, A (1960). La contribución directa 1821-1852. Revista de Ciencias Económicas, XLVIII(10): Serie IV (separata).

Fradkin, R. (1997). Entre la ley y la práctica: la costumbre en la campaña bonaerense de la primera mitad del siglo xIx. Anuario del IEHS, 12, 141-156.

Garavaglia, J. C. (1999). Pastores y labradores de Buenos Aires. Una historia agraria de la campaña bonaerense, 1700-1830. Buenos Aires: Ediciones de la Flor.

Garavaglia, J. C. (2003). Ejército y milicia: los campesinos bonaerenses y el peso de las exigencias militares, 1810-1860, Anuario del IEHS, 18, 153-187.

Garavaglia, J. C. (2004). La economía rural en la campaña de Buenos Aires vista a través de sus precios: 1756-1852. En R. Fradkin y J. C. Garavaglia (eds.), En busca de un tiempo perdido. La economía de Buenos Aires en el país de la abundancia 1750-1865 (pp. 107-158). Buenos Aires: Prometeo.

Garavaglia, J. C. y Gautreau, P. (comps.) (2011). Mensurar la tierra controlar el territorio. América Latina, siglos XVIII y XIX. Rosario: Prohistoria.

Gelman, J. y Santilli, D. (2006). De Rivadavia a Rosas. Desigualdad y crecimiento económico. En O. Barsky (dir.), Historia del capitalismo agrario pampeano (T. III). Buenos Aires: Universidad de Belgrano/Siglo XXI.

\section{(1) (1) $(9$}


Gelman, J. y Santilli, D. (2011). ¿Cómo explicar la creciente desigualdad? La propiedad de la tierra en Buenos Aires entre 1839 y 1867. En J. Gelman (ed.), El mapa de la desigualdad en la Argentina del siglo XIX (pp. 171-218). Rosario: Prohistoria

Gelman, J.y Santilli, D. (2013). Movilidad social y desigualdad en el Buenos Aires del siglo xIx: el acceso a la propiedad de la tierra entre el rosismo y el orden liberal. Hispanic American Historical Review, 93(4), 659-684.

Gelman, J. y Santilli, D. (2015). Salarios y precios de los factores en Buenos Aires, 1770-1880: una aproximación a la distribución funcional del ingreso en el largo plazo. Revista de Historia Económica, 33, 153-186.

Infesta, M. E. (2003). La Pampa criolla. Usufructo y apropiación privada de tierras públicas en Buenos Aires, 1820-1850. La Plata: Archivo Histórico de la Provincia de Buenos Aires.

Infesta, M. E. y Valencia, M. (1987). Tierras, premios y donaciones, 1830-1860. Anuario IEHS, 2, 177-213.

Irigoin, M. A. (2006). Las contribuciones directas en Buenos Aires. En L. Jáuregui (coord.), De riqueza e inequidad. El problema de las contribuciones directas en América Latina, siglo XIX (pp. 47-77). México: Instituto Mora.

Jáuregui, L. (coord.) (2006). De riqueza e inequidad. El problema de las contribuciones directas en América Latina, siglo XIx. México: Instituto Mora.

Jong, I. de (2007). Acuerdos y desacuerdos: política estatal e indígena en la frontera bonaerense (1856-1866). En R. Mandrini, A. Escobar Ohmstede y S. Ortelli (eds.), Sociedades en movimiento. Los pueblos indígenas de América Latina en el siglo XIX. Anuario del IEHS, 47-61.

Lanteri, S. y Pedrotta, V. (2009). Mojones de piedra y sangre en la pampa bonaerense. Estado, sociedad y territorio en la frontera sur durante la segunda mitad del siglo XIX. Revista de Estudios Trasandinos, 15, 101-129.

Miguez, E. (2008). Historia económica de la Argentina. De la conquista a la crisis de 1930. Buenos Aires: Sudamericana

Rosal, M. y Schmit, R. (2004). Las exportaciones pecuarias bonaerenses y el espacio mercantil bonaerense (1768-1854). En R Fradkin y J. C. Garavaglia (eds.), En busca de un tiempo perdido. La economía de Buenos Aires en el país de la abundancia (pp. 159193). Buenos Aires: Prometeo.

Ratto, S. (2006). Ni unitarios ni rosistas. Estrategias políticas interétnicas en Buenos Aires (1852-1857). Etudos de História, 13(2), 13-33.

Ratto, S. (2012). "Haremos lo posible por asegurar y tranquilizar la frontera". La defensa de la frontera bonaerense durante la década de 1850. En J. C. Garavaglia, J. Pro Ruiz y E. Zimmermann (eds.), Las fuerzas de la guerra en la construcción del 
Estado con América Latina, siglo XIX (pp. 351-380). Rosario: Prohistoria/Universitat Pompeu Fabra.

Registro Estadístico del Estado de Buenos Aires de 1854 (1855). Buenos Aires: Imprenta Porteña.

Sabato, H. (1989). Capitalismo y ganadería en Buenos Aires: la fiebre del lanar 1850-1890.

Buenos Aires: Sudamericana.

Santilli, D. (2010). El papel de la tributación en la formación del Estado. La contribución directa en el siglo xix en Buenos Aires. América Latina en la Historia Económica, 33, 33-63.

Valencia, M. (2005). Tierras públicas, tierras privadas. Buenos Aires 1852-1876. La Plata:

Archivo Histórico de la Provincia de Buenos Aires.

\section{OTRAS FUENTES}

\section{Archivos}

AGN Archivo General de la Nación, Argentina.

AнрвA Archivo Histórico de la Provincia de Buenos Aires, Argentina.

ACEPB Archivo del Colegio de Escribanos de la Provincia de Buenos Aires, Argentina.

\section{Bibliografía}

Barcos, M. F. (enero-abril, 2013). Los derechos de propiedad ejidal en el contexto desamortizador Iberoamericano. La campaña de Buenos Aires, siglo xIX, América Latina en la Historia Económica. Revista de Investigación, 20(1), 98-125.

Gelman, J. y Santilli, D. (2007). Entre la eficiencia y la equidad. Los desafíos de la reforma fiscal en Buenos Aires. Primera mitad del siglo XIX, Revista de Historia Económica, segunda época (3), 491-520.

Registro Oficial del Gobierno de Buenos Aires (1856). Buenos Aires: Imprenta de El Orden.

\section{(ㅇ)(1)(3)}

